\title{
Zhao Yanbo
}

\section{A Chinese Perspective on}

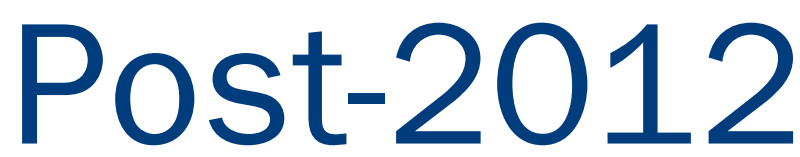

Burden sharing

The issue of climate change is a major challenge for humankind. ${ }^{1}$ It concerns the ways of survival and development. We need the common efforts of all members of the international community to tackle the problem.

Zhao Yanbo is Political Counsellor and Deputy Head of Mission in the Chinese Embassy in New Zealand and currently the Chargé d'affaires. He entered the Ministry of Foreign Affairs of China in 1987 and began his diplomatic career after graduation from the University of Xi'an in international studies and the University of Foreign Affairs of China. In China he worked in the Department of West Asian and North African Affairs and then the Department of North American and Oceanian Affairs in the ministry. Overseas he has served in five Chinese embassies, in Egypt, Vietnam, Canada, Papua New Guinea and New Zealand respectively.
Climate change is, in essence, an issue about development. In the past 200 years the emissions of developed countries during the process of industrialisation have been the main contributor to climate change. Of the total amount of carbon dioxide emissions from the burning of fossil fuels, developed countries contributed 95\% from the Industrial Revolution to 1950, and 77\% from 1950 to 2000. It has to be acknowledged, therefore, that developed countries should take the larger part of the responsibility for solving the problem due to their past emissions.

As countries differ in terms of stage of development, level of scientific and technological capability and national conditions, we believe our endeavour to combat climate change should be guided by the following principles.

First, we need a comprehensive programme of measures that recognises the importance of sustainable development. There needs to be a sound balance between economic growth and environmental protection to achieve the win-win result of both development and tackling climate change.

Second, we need to adhere to the principle of common but differentiated responsibilities. On one side, both developed and developing countries should work together and share responsibilities of adopting mitigation and adaptation measures to address climate change. On the other, developed countries should take responsibility for their historical emissions and current high per capita emissions, making explicit commitments to take the lead in emission reductions.

Third, we need to promote both mitigation and adaptation. For developing countries, adaptation is more realistic and urgent.

Fourth, we need to adhere to the main channel for tackling climate change, namely the United Nations Framework Convention on Climate Change (UNFCCG), and the effective implementation of UNFCGG and its Kyoto Protocol.

Fifth, we need policies to address technology transfer and provide funding support. Developed countries have a responsibility to promote technology transfer and provide 
funding to help developing countries improve their mitigation and adaptation capabilities.

In December 2007 the international community adopted the 'Bali Road Map', which is an important milestone in the global endeavour to tackle climate change. It charts the course and sets the timetable for the negotiations for a post-2012 arrangement. This year there have been meetings in Bangkok and Bonn, with others to follow. It is crucial that every effort is made to implement the Bali Road Map and secure a new agreement by the end of 2009. The international community should work together to ensure that there is progress in the negotiations.

China is among the countries that will be most seriously affected by the negative impacts of climate change. Looking at China's emissions, it is necessary to take into account the following three factors.

First, China is a developing country in the process of industrialisation and modernisation. Imbalances exist in terms of development between the urban and rural areas, among different regions, and between the economic and the social sectors, and average living standards still need improving. China's core task now is to develop.

Second, China's per capita emissions are relatively low, particularly if calculated in cumulative terms. A significant share of China's total emissions falls into the category of subsistence necessary to meet people's basic needs.

Third, as a result of changes in the international division of labour and manufacturing relocation, China faces the challenge of international transfers of emissions - from the developed world to the developing world.

The Chinese government, with a responsible attitude towards the Chinese people and the whole world, takes the issue of climate change very seriously. In the past two decades China has adopted a sustainable development strategy and undertaken a series of economic reforms, including conserving energy, improving structures, raising efficiency and promoting afforestation. This has saved 800 million tonnes of standard coal, equivalent to a reduction in carbon dioxide emissions of 1.8 billion tonnes, which is a significant contribution to the global effort to curb emissions

The Chinese government has also set up the National Leading Group headed by Premier Wen Jiabao to improve coordination between different departments. Public awareness of the need for mitigation is growing. Further,
China has adopted the national climate change programme, which sets various targets - for instance, the energy intensity per unit of GDP will be reduced by $20 \%$ by 2010 based on 2005 levels, the percentage of energy coming from renewable sources will be increased from $7.5 \%$ to $10 \%$, the total discharge of major pollutants will be cut by $10 \%$, and forest coverage will be increased to $20 \%$ from $18.2 \%$. We are firmly committed to meeting these targets.

China will also make continued efforts to strengthen the nation's adaptation capacity in the fields of agriculture, natural and ecological systems and water resources, it will place great importance on disaster prevention and reduction, and it will seek to minimise the losses caused by disastrous weather conditions and extreme climate events.

China is actively involved in multilateral forums on climate change, including and the relevant activities of the Asia Pacific Partnership on Clean Development and Climate, the International Methane to Market Partnership and the Carbon Sequestration Leadership Forum. China has held bilateral negotiations on climate change with a number of countries, including the EU, Japan, Canada, India and Australia, issued a joint statement on climate change with France and a joint communiqué on strengthening environment cooperation with Japan, and deepened negotiations and coordination on climate change with Brazil, Mexico, South Africa and other countries.

In April 2008 the New Zealand prime minister, Helen Clark, visited China. During her meeting with Wen Jiabao, the Chinese premier specifically invited New Zealand to play a role in assisting with China's transition to a low carbon economy through greenhouse gas mitigation. China is ready to cooperate with New Zealand on such issues.

In summary, China, in accordance with the requirements of UNFCGG and its Kyoto Protocol, and particularly the principle of common but differentiated responsibilities, actively promotes negotiations on the implementation of the Bali Road Map and is ready to work unremittingly with the rest of the international community to achieve harmonious, clean and sustainable development in the world.

\footnotetext{
1 This is a slightly edited version of the address by Zhao Yanbo at the Post-2012 Burden Sharing symposium, 29 July 2008, Wellington, jointly hosted by the European Union Centres Network and the Institute of Policy Studies.
} 